\title{
MECHANICAL BEHAVIOR AND CATENARY ACTION OF RESTRAINED STEEL BEAM UNDER FIRE
}

\author{
Run-Min Ding ${ }^{1}$, Sheng-Gang Fan ${ }^{1, *}$, He-Yang Gui ${ }^{2}$, Cheng-Liang Liu ${ }^{3}$ and Hang Zhou ${ }^{1}$ \\ ${ }^{1}$ Key Laboratory of Concrete and Prestressed Concrete Structures of Ministry of Education, School of Civil Engineering, Southeast University, Jiulonghu Campus, Nanjing 211189, China \\ ${ }^{2}$ China Northwest Architecture Design and Research Institute Co. Ltd, Xi'an 710018, China \\ ${ }^{3}$ East China Architectural Design \& Research Institute, Shanghai 200002, China \\ *(Corresponding author: E-mail: 101010393@seu.edu.cn)
}

\section{A B S T R A C T}

To investigate the mechanical behavior and catenary action of restrained steel beam under fire, experiments were performed on five H-section restrained steel beams exposed to ISO-834 standard fire. At first, mechanical property tensile tests were performed on 3 room-temperature specimens and 8 high-temperature specimens, and variation laws of the material properties of steel materials with temperature rising were investigated by the high-temperature steady-state tests. Through the fire experiments, the temperature data, mid-span deflections and failure modes of all specimens were obtained. The experimental results show that: (1) a restrained steel beam is prone to in-plane buckling failure under fire; (2) the loading ratio $\mathrm{n}$ and axial restraint stiffness $\mathrm{Kx}$ have great influences on the catenary action of restrained steel beam under fire; (3) when the loading ratio $n$ is constant, the greater the axial restraint stiffness $\mathrm{Kx}$, the later the catenary action occurs; when the axial restraint stiffness $\mathrm{Kx}$ is constant, the greater the loading ratio $\mathrm{n}$, the earlier the catenary action occurs.

A R T I C LE H I S T O RY

\begin{tabular}{l} 
Received: $\quad$ 17 July 2020 \\
$\begin{array}{l}\text { Revised: } \\
\text { Accepted: }\end{array} \quad$ 30 March 2021 \\
K E Y W O R D S \\
\hline Steel beams with constraints; \\
Mechanical behavior; \\
Catenary action; \\
Loading ratio; \\
Axial restraint stiffness
\end{tabular}

Copyright $\odot 2021$ by The Hong Kong Institute of Steel Construction. All rights reserved

\section{Introduction}

Design methods for the buildings at room temperature have been well established. But the building safety is always under the threat of fires. Fig. 1 displays the fire statistics of China in the past ten years [1], and most of the economic loss and casualties are caused by structural fires. Therefore, the mechanical behavior and fire resistance of engineering buildings under fire have attracted increasing attention by researchers in China and abroad.

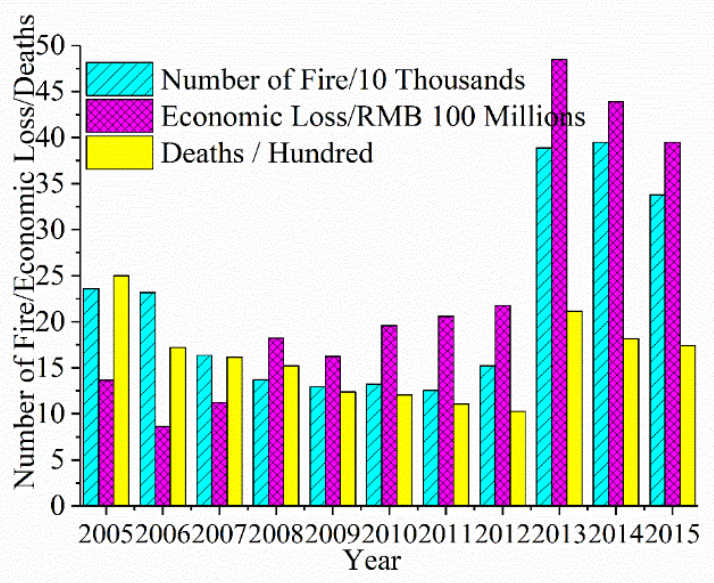

Fig. 1 Statistics of fire situation in China

The existing researches [2-3] primarily focus on the material properties of steel at high temperatures and the mechanical behavior of single component under fire exposure. However, the problem of fire safety of the whole structure cannot be simply divided into the fire resistance of single members. The BRE conducted a series of fire tests on an 8-story steel frame in Cardington [4], and the results show that: the steel beam considering the structural integrity action has a higher fire-resistant performance than the simply supported steel beam; and in the whole structure, the catenary action is mainly caused by the constraints applied at both ends of steel beam, which can greatly improve the bearing capacity of beam.

Numerous studies have been carried out on the fire-resistant performance of restrained steel beam at elevated temperatures, and relevant design methods have been proposed. However, a comprehensive and systematic study on the formation mechanism and judgement principle of catenary action has not been conducted. Burgess et al. [5] conducted experiments on the behaviors of steel beam under fire exposure. The research suggested that the bearing capacity of a steel beam at high temperatures can be greatly improved when its both ends can provide strong constraints. Usmani et al. [6] theoretically analyzed the deformation and internal force in the restrained steel beam caused by thermal expansion with the consideration on the axial and rotational restraint stiffness, and a formula for calculating the deformation and internal force in the beam was given. Through fire tests, Liu et al. [7] investigated the influencing factors on the fire resistance of restrained steel beams, including loading ratio, axial and rotational constraints, which indicated that the fire-resistant performance of restrained steel beam is better than that of unrestrained steel beam due to end constraints of beam. Moss et al. [8] performed finite element analysis on a group of restrained steel beams and composite beams under fire exposure, and it was found that the end constraint condition of steel beam has a considerable effect on its fire resistance. Wang and Yin [9-13] investigated the formation process and mechanism of catenary action in the steel beam; and a simplified calculation formula for the deflection of steel beam was established considering the catenary action. Through numerical simulation and analysis, Dwaikat and Kodur [14] proposed a method for evaluating the fire-resistant performance of restrained steel beam by taking a lot of influencing factors in account, such as end constraint, connection construction and temperature gradient. Li et al. [15-18] found that there are large internal temperature forces in the restrained steel beam under fire, and the distribution of stress and strain in the section was given. In addition, a simple method was presented to calculate the maximum deflections of steel beam under high temperatures. Cong and $\mathrm{Li}$ et al. $[19,20]$ tested $6 \mathrm{H}-$ section steel beams under fire exposure to investigate the effects of load intensity and end constraints on the fire resistance of beam. During the test, some specimens produced obvious catenary action, and the coupling of local buckling and lateral-torsional buckling occurred in the steel beam under the combined action of axial force and restraining moment. Luan and Xi [21] analyzed the behaviors of steel beam subjected to fire under different restraint conditions and obtained the influencing laws of restraint conditions on the critical temperature of beam. Ma [22] studied the catenary effect of honeycombed steel beam with end restraint under fire, and he compared and analyzed the mechanical behaviors of honeycombed beam and solid-web beam under fire. Iqbal et al. [23] proposed a simplified analytical method to predict the mechanical behavior of restrained steel beam under fire. Du et al. [24] put forward a modified method to calculate the temperature rising curve of steel beam exposed to natural fire. Liu [25] investigated the catenary actions of restrained corrugated web steel beams with both uniform temperature distribution and non-uniform temperature distribution across the section. The fire resistance design suggestions of corrugated web 
beams with or without end restraints and different cross-section temperature distribution were given, and the fire resistance design of corrugated web beams with different cross-section temperature distribution was transformed into that of flat web steel beams with uniform temperature distribution.

To study the catenary action in the restrained steel beam under fire, the experiments were conducted on $5 \mathrm{H}$-section restrained steel beams in the fire test furnace, and the furnace temperatures, specimen temperatures and mid-span deflections of all specimens were obtained. The influencing factors of the catenary action of restrained steel beam under fire were explored, and the influences of loading ratio and axial restraint stiffness were emphatically investigated.

\section{Mechanical properties of materials}
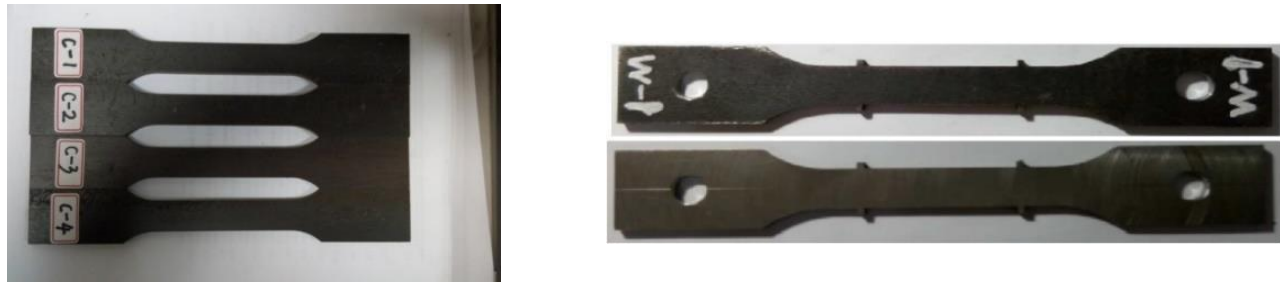

(a) Room-temperature test coupons
Because there is no essential difference in material properties between Q235 and steel materials with higher yield strength, and Q235 has a lower cost, the restrained steel beams in this test are made of Q235. A series of tensile tests were conducted to accurately obtain the mechanical properties of Q235 at different temperatures.

\subsection{Test coupons}

The tensile coupons that tested at room temperature and high temperatures were fabricated according to the requirements of Metallic materials-Tensile testing Part1: Method of test at room temperature [26] and Metallic materialsTensile testing Part2: Method of test at elevated temperature [27], respectively. Fig. 2 shows the finished test coupons. Table 1 and Table 2 provide the number and size of test coupons at room temperature and high temperatures, respectively.

Fig. 2 Material mechanical property test coupons

Table 1

Number, size and mechanical test results of test coupons at room temperature

\begin{tabular}{|c|c|c|c|c|c|c|c|c|c|}
\hline \multirow[b]{2}{*}{ Number } & \multicolumn{2}{|c|}{ Original size } & \multicolumn{3}{|c|}{ Measured size } & \multicolumn{4}{|c|}{ Mechanical property parameter value } \\
\hline & $\begin{array}{c}\text { Thickness } t_{0} \\
\quad / \mathrm{mm}\end{array}$ & $\begin{array}{l}\text { Width } b_{0} \\
/ \mathrm{mm}\end{array}$ & $\begin{array}{l}\text { Thickness } t \\
/ \mathrm{mm}\end{array}$ & $\begin{array}{l}\text { Width } \\
b \\
/ \mathrm{mm} \\
\end{array}$ & $\begin{array}{c}\text { Area } A \\
/ \mathrm{mm}^{2}\end{array}$ & $\begin{array}{c}\text { Yield strength } \\
f_{\mathrm{y}} / \mathrm{N} / \mathrm{mm}^{2}\end{array}$ & $\begin{array}{l}\text { Ultimate strength } \\
\qquad f_{\mathrm{u}} / \mathrm{N} / \mathrm{mm}^{2}\end{array}$ & $\begin{array}{l}\text { Elastic modulus } \\
\qquad E / \mathrm{N} / \mathrm{mm}^{2}\end{array}$ & Elongation $/ \%$ \\
\hline $\mathrm{C}-1$ & 8 & 20 & 7.50 & 19.98 & 149.85 & 293 & 429.3 & $2.07 \times 10^{5}$ & 38.19 \\
\hline $\mathrm{C}-2$ & 8 & 20 & 7.53 & 20.02 & 150.75 & 285 & 423.5 & $2.04 \times 10^{5}$ & 36.83 \\
\hline $\mathrm{C}-3$ & 5.5 & 20 & 5.43 & 19.98 & 108.49 & 305 & 443.7 & $2.17 \times 10^{5}$ & 39.40 \\
\hline C-4 & 5.5 & 20 & 5.44 & 20.03 & 108.96 & 310 & 444.5 & $2.11 \times 10^{5}$ & 38.57 \\
\hline
\end{tabular}

Table 2

Number, size and Mechanical test results of test coupons at high temperatures

\begin{tabular}{|c|c|c|c|c|c|c|c|c|c|c|}
\hline \multirow[b]{2}{*}{ Number } & \multirow[b]{2}{*}{$\begin{array}{c}\text { Temperature } \\
\text { condition } \\
/{ }^{\circ} \mathrm{C}\end{array}$} & \multicolumn{2}{|c|}{ Original size } & \multicolumn{2}{|c|}{ Measured size } & \multicolumn{3}{|c|}{ Mechanical property parameter value } & \multicolumn{2}{|c|}{ Reduction factor } \\
\hline & & $\begin{array}{c}\text { Thick } \\
t_{0} \\
/ \mathrm{mm}\end{array}$ & $\begin{array}{l}\text { Width } \\
b_{0} \\
/ \mathrm{mm}\end{array}$ & $\begin{array}{l}\text { Thick } \\
t \\
/ \mathrm{mm}\end{array}$ & $\begin{array}{l}\text { Width } \\
b \\
/ \mathrm{mm}\end{array}$ & $\begin{array}{c}\text { Yield strength } \\
f_{\mathrm{yT}} \\
\mathrm{N} / \mathrm{mm}^{2}\end{array}$ & $\begin{array}{c}\text { Ultimate } \\
\text { strength } \\
f_{\mathrm{uT}} \\
\mathrm{N} / \mathrm{mm}^{2} \\
\end{array}$ & $\begin{array}{c}\text { Elastic } \\
\text { modulus } \\
E_{\mathrm{T}} \times 10^{5} \mathrm{~N} / \mathrm{mm}^{2}\end{array}$ & $f_{\mathrm{y} \mathrm{T}} / f_{\mathrm{y}}$ & $E_{\mathrm{T}} / E$ \\
\hline W-0 & 20 & 4 & 15 & 3.84 & 14.94 & 309 & 439 & 2.05 & 1.000 & 1.000 \\
\hline W-1 & 100 & 4 & 15 & 3.93 & 14.91 & 305 & 438 & 2 & 0.987 & 0.976 \\
\hline W-2 & 200 & 4 & 15 & 3.92 & 14.94 & 295 & 534 & 1.85 & 0.955 & 0.902 \\
\hline $\mathrm{W}-3$ & 300 & 4 & 15 & 3.89 & 14.95 & 298 & 521 & 1.67 & 0.965 & 0.815 \\
\hline W-4 & 400 & 4 & 15 & 4.02 & 14.8 & 302 & 398 & 1.42 & 0.977 & 0.693 \\
\hline W-5 & 500 & 4 & 15 & 4.04 & 14.86 & 220.6 & 263 & 1.294 & 0.714 & 0.631 \\
\hline W-6 & 600 & 4 & 15 & 3.99 & 14.9 & 130.1 & 140.4 & 0.736 & 0.421 & 0.359 \\
\hline W-7 & 700 & 4 & 15 & 3.98 & 15.04 & 65.3 & 66.94 & 0.193 & 0.211 & 0.094 \\
\hline W-8 & 800 & 4 & 15 & 3.97 & 14.82 & 43.45 & 47.66 & 0.175 & 0.141 & 0.085 \\
\hline
\end{tabular}

There are 13 tensile coupons in total, of which 4 are room-temperature coupons and the other 9 are high-temperature coupons. Room-temperature coupons $\mathrm{C}-1$ and $\mathrm{C}-2$ were cut from the flange of steel beam, and coupons C-3 and $\mathrm{C}-4$ were cut from the web of steel beam. For high-temperature coupons, each temperature condition corresponds to one coupon.

\subsection{Test method}

Room-temperature tensile tests were conducted by following the relevant requirements in the code [26]. The loading of the tensile tests was controlled by displacement and divided into two stages. In the first stage of loading process, the initial elastic modulus and yield strength were mainly measured, and the test coupons were stretched to yield at a speed of $0.5 \mathrm{~mm} / \mathrm{min}$. In the second stage of loading process, the ultimate tensile strength was measured and the test coupons were stretched to fracture at a speed of $4 \mathrm{~mm} / \mathrm{min}$. The tensile deformation of the gauge length of test coupon was measured by a normal temperature extensometer.

The high-temperature tensile test includes two methods: steady-state test and transient-state test $[28,29]$. In the steady-state test method, the coupon is heated to a predetermined temperature and keep it constant, then tensile load is increased until the coupon is damaged. In the transient-state test method, the coupon is loaded to a constant stress level at room temperature, then the temperature is increased at a certain speed until the coupon is damaged. In this study, the mechanical properties of the material at different temperatures were 
tested through the steady-state method, with the controlled temperature conditions chosen as $20{ }^{\circ} \mathrm{C}, 100{ }^{\circ} \mathrm{C}, 200{ }^{\circ} \mathrm{C}, 300{ }^{\circ} \mathrm{C}, \ldots, 800{ }^{\circ} \mathrm{C}$. The existing results $[30,31]$ showed that the furnace temperature is nearest to the surface temperature of coupon when the heating rate of coupon is set at a speed of $20{ }^{\circ} \mathrm{C} / \mathrm{min}$.

According to the requirements in the code [27], the steps of the steady-state test are listed as follows: (1) The heating furnace is heated to a controlled temperature condition at a speed of $20^{\circ} \mathrm{C} / \mathrm{min}$ and then the temperature is kept constant for $30 \mathrm{~min}$ to ensure that the measured furnace temperature is as consistent as possible with the surface temperature of coupon. (2) In the process of heating-up and heat-preservation, the testing device should be constantly adjusted to ensure that the load applied by the testing machine is 0 , that is, the coupon is allowed to expand freely. (3) Finally, the coupon is loaded to damage by displacement control, and the temperature remains unchanged within the whole loading period. The loading process is controlled by displacement and can also be divided into two stages, and the specific loading method is the same as the tensile tests at room temperature.

\subsection{Test results}

The failure phenomena in the tensile tests at room temperature and high temperatures are illustrated in Fig. 3: (1) Every coupon underwent a long plastic deformation stage from tensile to fracture, there was distinct necking phenomenon after fracture, and the material exhibited excellent extensibility. (2) For high-temperature tensile coupons, the surface of coupon showed a bright original color at $200{ }^{\circ} \mathrm{C}$; at $300{ }^{\circ} \mathrm{C} \sim 500^{\circ} \mathrm{C}$, the surface color of coupon changed from light yellow to dark blue; and at $600{ }^{\circ} \mathrm{C} \sim 800{ }^{\circ} \mathrm{C}$, the surface color of coupon became dark and there was a film on the surface. Finally, the surface color of coupon gradually changed from dark black to dark brown with further increase in temperature.

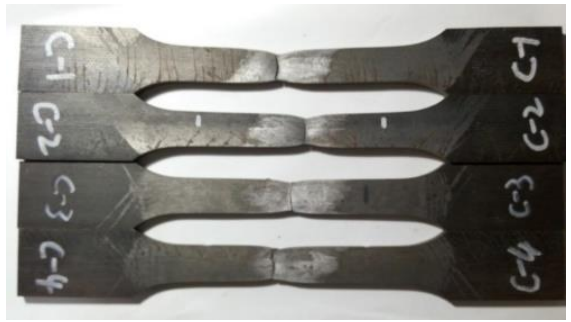

(a) Room-temperature test coupons

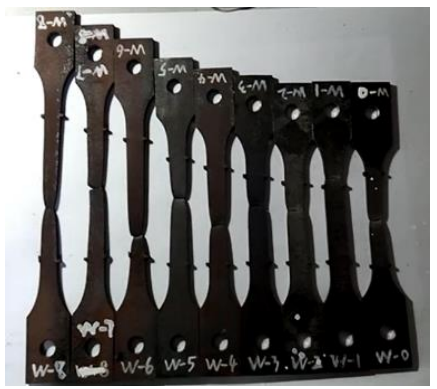

(b) High-temperature test coupons

Fig. 3 Failure phenomenon of the material mechanical property test coupons

The tensile test results at room temperature and high temperatures are given in Table 1 and Table 2, respectively. The stress-strain curves of test coupons are shown in Fig. 4(a) and (b). From Tables 1 and 2 and Fig. 4, the following conclusions can be obtained: (1) With temperature rising, the yield plateau of steel gradually disappears. Because the research object of this paper is the catenary action of restrained steel beam under fire, which belongs to the range of large deformation of components, the maximum strain of steel material in the restrained steel beam under fire may exceed $2 \%$. (2) At a temperature range of $200{ }^{\circ} \mathrm{C} \sim 300{ }^{\circ} \mathrm{C}$, the coupon appears the phenomenon of blue brittle, and the ultimate strength of steel is improved. Thereafter the yield strength and ultimate strength gradually decrease with temperature rising. At temperature of $600{ }^{\circ} \mathrm{C}$, the degradation of the strength of steel is obvious. At temperature of $800{ }^{\circ} \mathrm{C}$, the strength of steel is only equal to approximately $10 \%$ of the strength at normal temperature. (3) The elastic modulus of steel descends with temperature rising. At temperature of $800{ }^{\circ} \mathrm{C}$, the elastic modulus of steel has an obvious degradation.

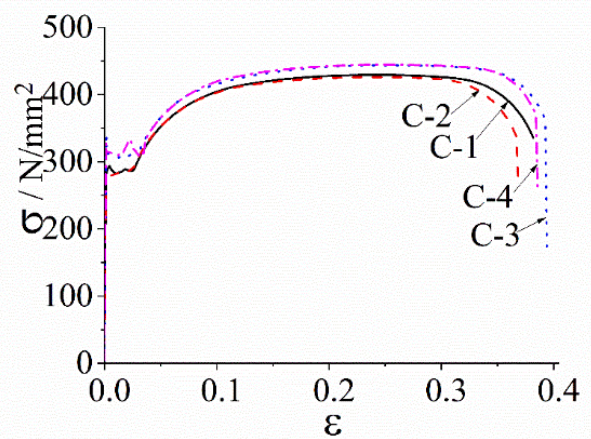

(a) Room-temperature test coupons

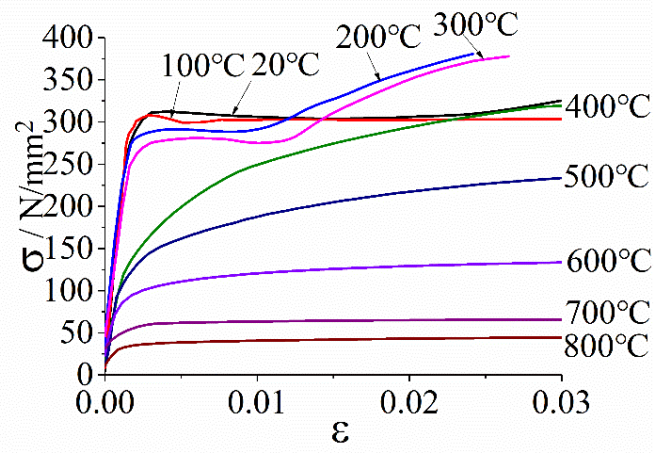

(b) High-temperature test coupons

Fig. 4 Stress-strain curves of test coupons

Table 2 gives the measured reduction coefficients for elastic modulus and yield strength of steel at high temperatures, and they were compared with the recommended values given by the Eurocode 3 (EN 1993-1-2) [32] and Chinese Technical code for fire safety of steel structure in buildings (CECS 200: 2006) [33], as shown in Fig. 5. It can be seen that from Fig. 5: (1) At different temperatures, the experimental values of yield strength reduction coefficient of steel are lower than those specified in the Eurocode 3 [32], but they are similar to those specified in the Chinese Technical code [33]. (2) At different temperatures, the experimental values of elastic modulus reduction coefficient of steel are similar to those specified in the Eurocode 3 [32], but substantially lower than those specified in the Chinese Technical code [33].

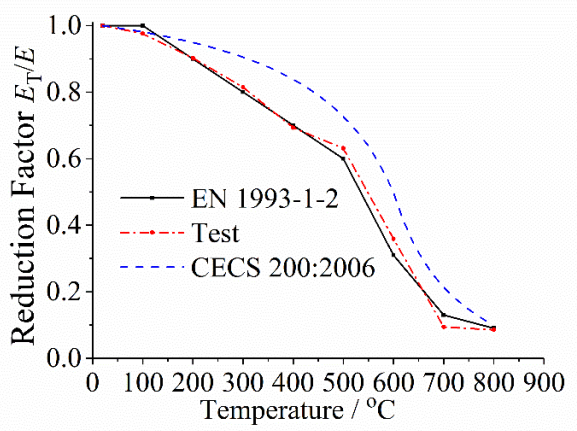

(a) Elastic modulus

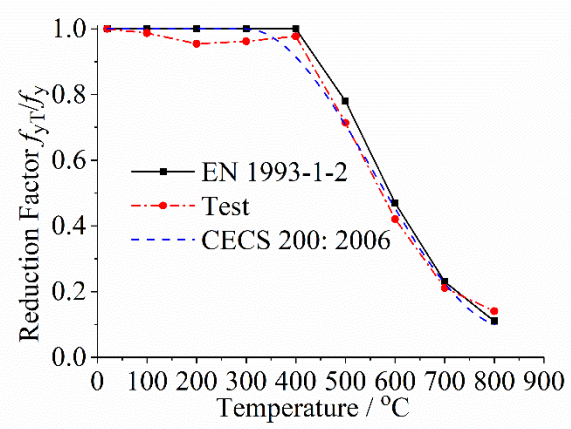

(b) Yield strength

Fig. 5 Comparisons of the reduction coefficients of steel at high temperatures 


\section{Fire test of steel beam with constraint}

Three-side heated tests were conducted on five $\mathrm{H}$-section restrained steel beams to investigate the influences of loading ratio and axial restraint stiffness on the development of catenary action. The failure mode, temperature data, midspan vertical deformation and loading-point vertical deformation of each specimen were obtained.

\subsection{Testing device}

The fire tests were carried out in a horizontal fire test furnace system, consist of heating equipment, loading equipment and data acquisition control equipment.
The heating equipment is composed of a furnace cavity, flame nozzle and thermocouple. The furnace cavity can be divided into left and right parts by setting refractory brick wall in the middle. In view of the size of the specimen, the fire test was only carried out through half furnace cavity, and its size is 3.13 $\mathrm{m} \times 1.88 \mathrm{~m}$ (length $\times$ width). The half furnace cavity has 4 flame nozzles and 4 thermocouples, which are employed for the heating-up of furnace cavity and air temperature monitoring, respectively. The temperature rise of the fire test furnace follows the ISO-834 fire curve, and the furnace is heated by burning natural gas. The exhaust ducts are arranged at the bottom of the furnace, which can keep the pressure in the furnace cavity stable and the temperature distribution uniform. Fig. 6(a) and (b) show the overall appearance and internal cavity of the horizontal fire furnace respectively.

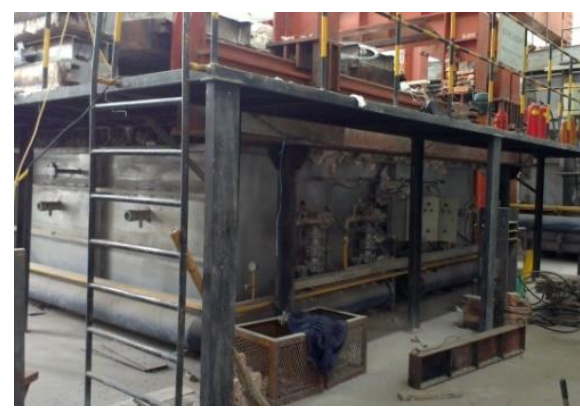

(a) Appearance of fire furnace

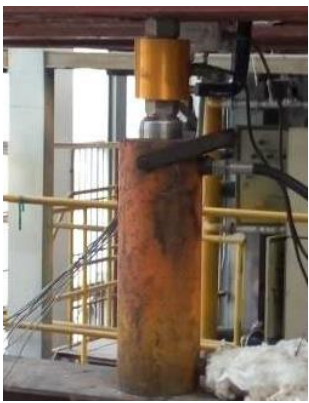

(d) Hydraulic jack and pressure senso

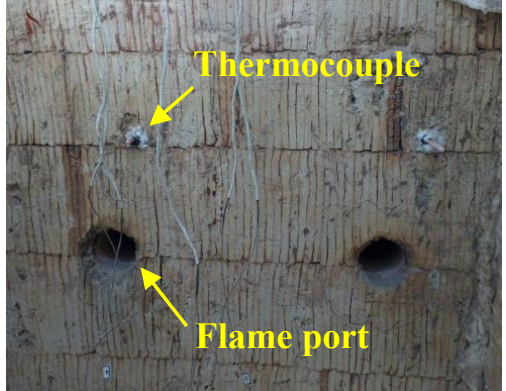

(b) Fire furnace interior

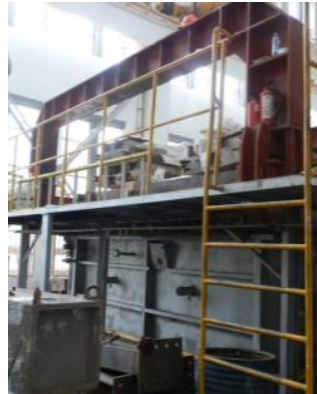

(c) Reaction frame

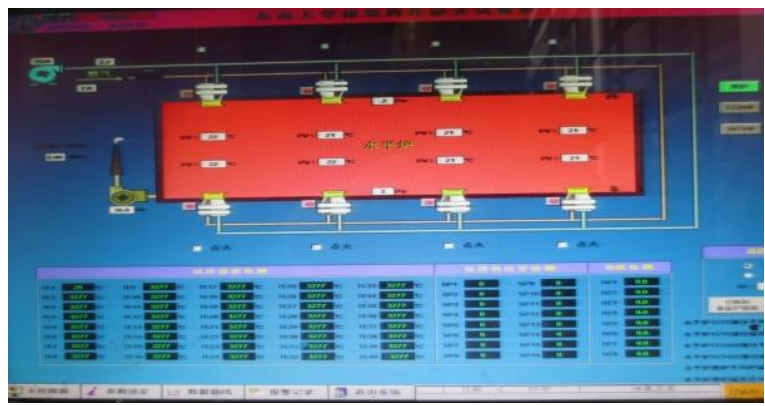

(e) Data presentation equipment

Fig. 6 Horizontal fire test equipment

The loading equipment mainly includes a $300 \mathrm{kN}$ hydraulic jack, a $200 \mathrm{kN}$ pressure sensor and a $500 \mathrm{kN}$ vertical reaction frame, as shown in Fig. 6(c) and (d). In the restrained steel beam fire test, the vertical load value applied to the specimen is relatively small. To accurately control all load levels, a $200 \mathrm{kN}$ pressure sensor was used in this fire test.

The data acquisition equipment is mainly composed of load collector, displacement collector and temperature collector, as shown in Fig. 6(e). The load

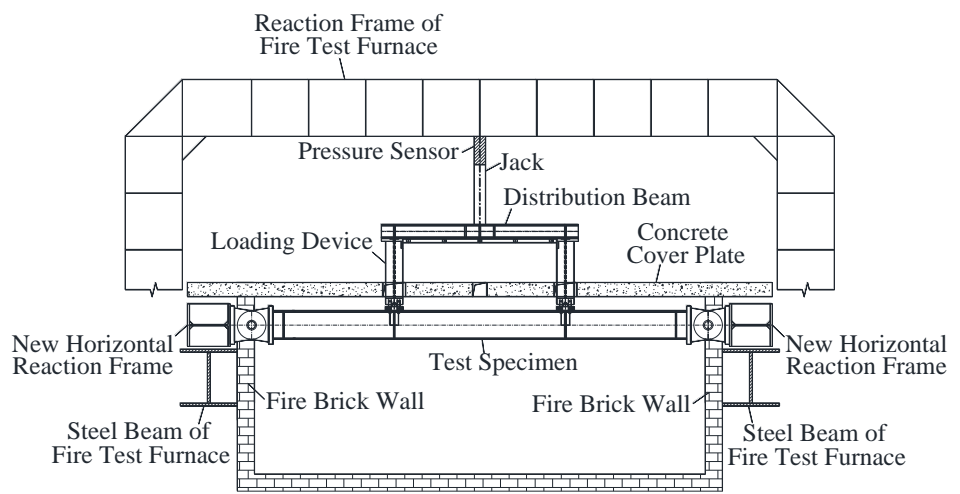

(a) Elevation was controlled to be constant and monitored by the pressure sensor, so the load collector is not utilized during the test. The specimen deformations were recorded by the displacement collector. Through 17 thermocouples arranged on each specimen and 4 thermocouples set in the furnace, the temperature acquisition controller can record and control all temperature data. Fig. 7(a) and (b) show the overall fire test devices of restrained steel beams.

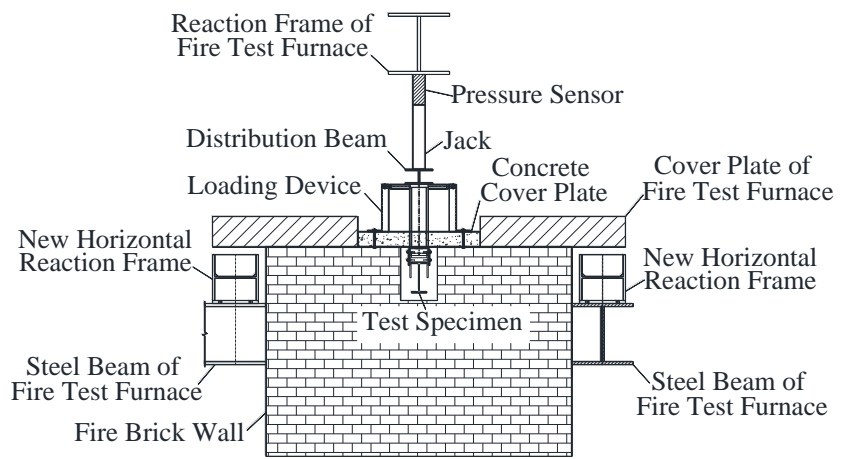

(b) Profile

Fig. 7 Overall fire test devices of restrained steel beams

\subsection{Design and manufacture of horizontal reaction frame}

To accurately simulate the different end constraint conditions of restrained steel beam under fire, a horizontal reaction frame was added to provide different axial restraint stiffnesses for the specimens. Fig. 8(a) shows the arrangement of the horizontal reaction frame set with "Constraint position 1" and "Constraint 
position 2". During the test, different sizes of axial restraint stiffness can be provided for the end of the specimen by changing the constraint position on the horizontal reaction frame, and the axial restraint stiffness provided by Constraint position 2 is greater than the axial restraint stiffness provided by Constraint position 1. Through numerical simulation and mechanical method, the axial restraint stiffnesses provided by Constraint positions 1 and 2 can be calculated, which are $1.29 \times 10^{8} \mathrm{~N} / \mathrm{m}$ and $2.087 \times 10^{8} \mathrm{~N} / \mathrm{m}$, respectively.
Fig. 8(b) illustrates the finished horizontal reaction frame composed of four edge beams. Edge beam A and Edge beam B adopt an H-shaped section, the section size is HW $300 \times 300 \times 10 \times 15$ and the material is Q345B, as shown in Fig. 8(c) and (d), respectively. The edge beams are connected with each other by flange joints. To prevent the four corners of the horizontal reaction frame from warping during the test, the Edge beams A and B are connected with the top steel beams of the furnace using split bolts at the four corners.

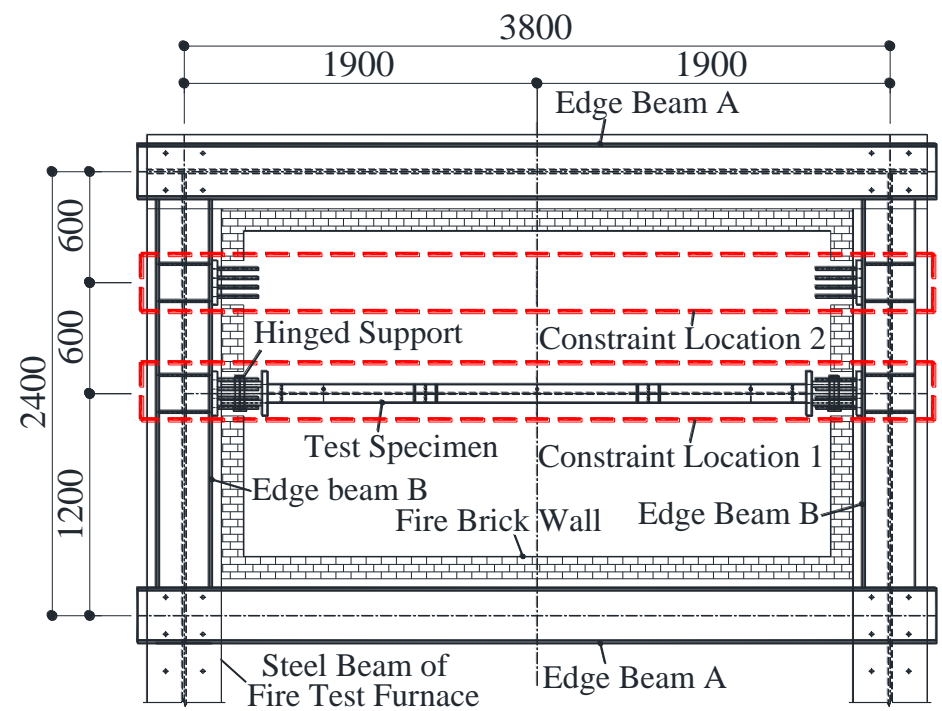

(a) Layout of horizontal reaction frame

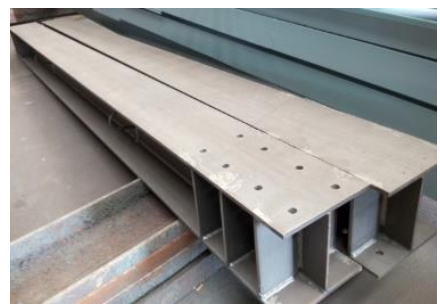

(c) Edge beam $\mathrm{A}$

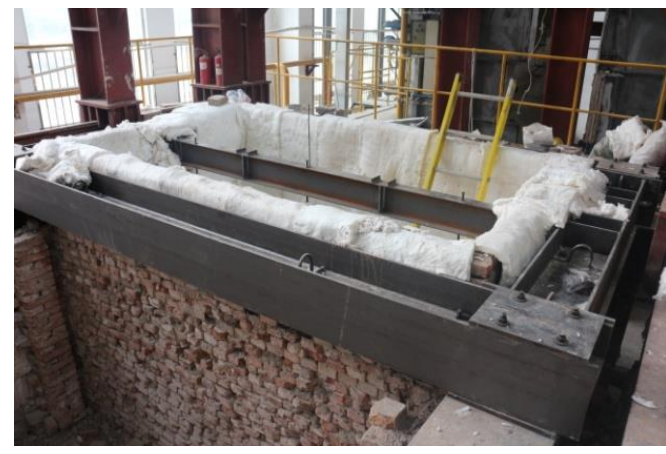

(b) Reaction frame appearance

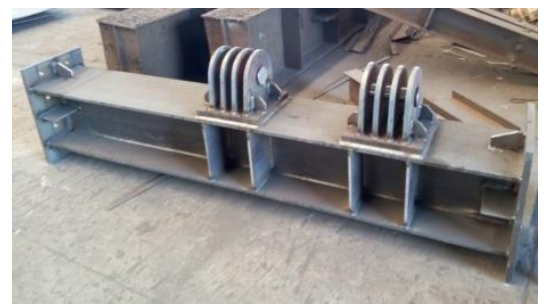

(d) Edge beam B

Fig. 8 New added horizontal reaction frame under fire test furnace

\subsection{Test specimens}

Q235B steel was selected as the material of the specimens, and the crosssection was the hot-rolled H-section. The length of specimen was selected as 3.2 $\mathrm{m}$ in considering of the furnace cavity size. To investigate the catenary action of restrained steel beam under fire, the specimen should be controlled to occur inplane bending deformation during the test, and the out-of-plane global instability or local buckling failure of plate should be avoided as far as possible. The finite element software ABAQUS [34] is used to simulate the restrained steel beam for many times, and the cross section of specimen was determined as HN200 $\times$ $100 \times 100 \times 5.5 \times 8$. According to the test method of references [35-39], the restrained steel beam fire test adopt the two-point loading mode, and the loading points are located at $1 / 3$ of the span. Two plates were welded to form a slot for fixing the loading device at the loading point of specimen. Fig. 9 illustrates the detailed dimensions of the specimen, and Fig. 10 shows the finished specimens.

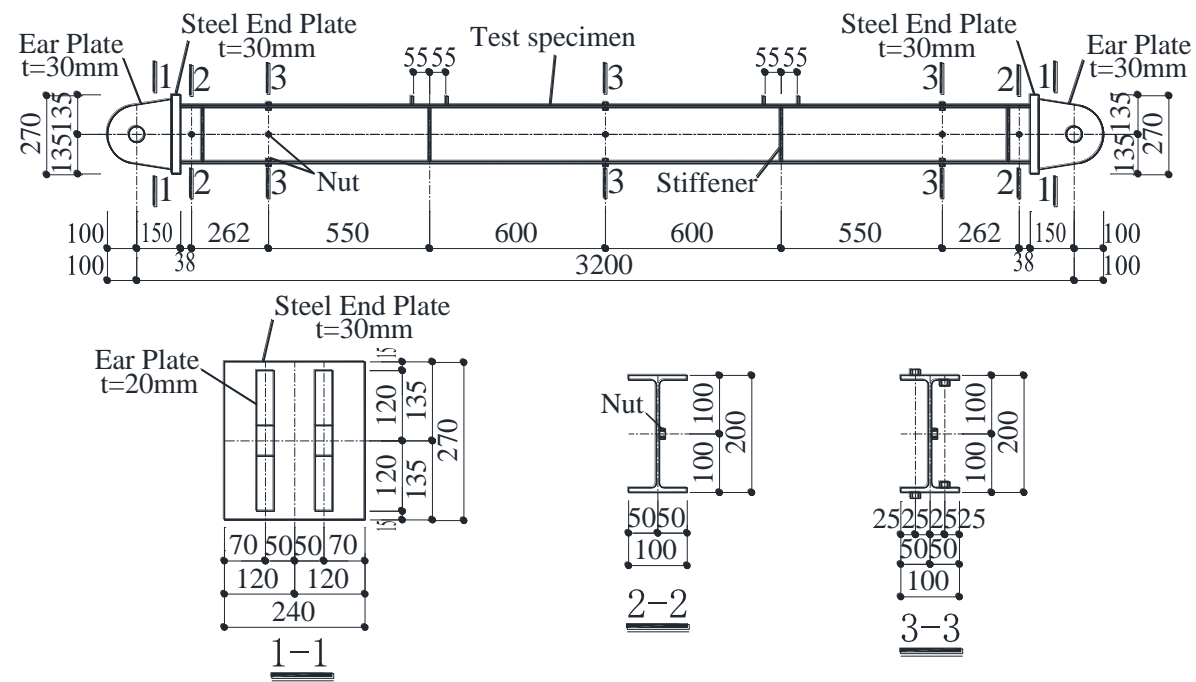

Fig. 9 Detailed dimensions of specimen 


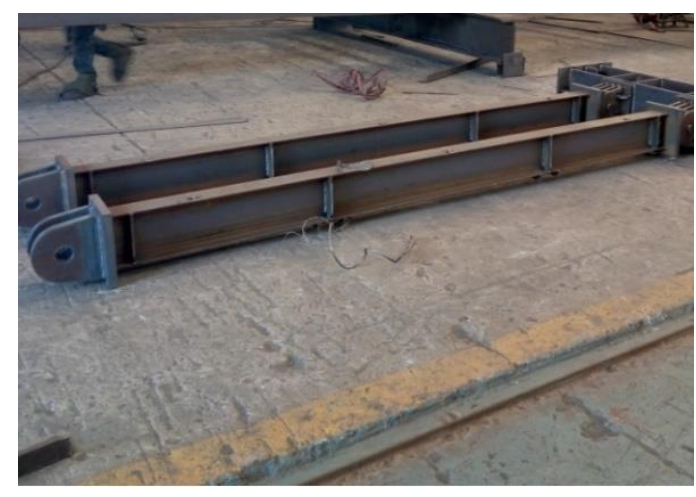

Fig. 10 Finished specimens

The detailed information for each specimen is shown in Table 3. To investigate the effect of loading ratio on catenary action, the specimens can be divided into two groups, B-1 and B-2 are in one group (with the same axial restraint stiffness $1.29 \times 10^{8} \mathrm{~N} / \mathrm{m}$, but different loading ratios), B-3 and B-4 are in the other (with the same axial restraint stiffness $2.087 \times 10^{8} \mathrm{~N} / \mathrm{m}$, but different loading ratios). To investigate the effect of axial restraint stiffness on catenary action, the specimens can also be divided into two groups, B-1 and B-3 are in one group (with the same loading ration 0.48 , but different axial restraint stiffnesses), B-2 and B-4 are in the other (with the same loading ration 0.34, but different axial restraint stiffnesses). The specimen B-5 is a repeat test of B-1, to verify the correctness of test results.

For specimens B1 B5, the thermocouple measurement points were put on five sections (section 1 5) along the length direction of the specimen, respectively $38 \mathrm{~mm}, 300 \mathrm{~mm}, 1450 \mathrm{~mm}, 2600 \mathrm{~mm}$, and $2862 \mathrm{~mm}$, away from the left end. For sections 2, 3 and 4, four thermocouple measurement points are set on the inner and outer sides of the flanges, and one on the middle of the web. For sections 1 and 5, only one thermocouple measurement point is put on the web. Among them, the thermocouple measurement points of section 2, section 3 and section 4 are mainly used to measure the temperature distribution around the same section and the temperature distribution along the length direction of different sections. Section 1 and section 5 are located near the supports and wrapped under fireproof cotton. Each specimen has a total of 17 thermocouple measurement points on its surface, as shown in Fig. 11.

Table 3

Detailed design parameters of test specimens

\begin{tabular}{ccccc}
\hline Specimen number & Sectional dimension & $\begin{array}{c}\text { Length } \\
(\mathrm{m})\end{array}$ & Loading ratio & Constraint position \\
\hline B-1 & & 3.2 & 0.48 & 1 \\
B-2 & & 3.2 & 0.34 & $1.29 \times 10^{8}$ \\
B-3 & HN200 $\times 100 \times 5.5 \times 8$ & 3.2 & 0.48 & 2 \\
B-4 & & 3.2 & 0.34 & 2 \\
B-5 & & 3.2 & 0.48 & $2.087 \times 10^{8}$ \\
\hline
\end{tabular}

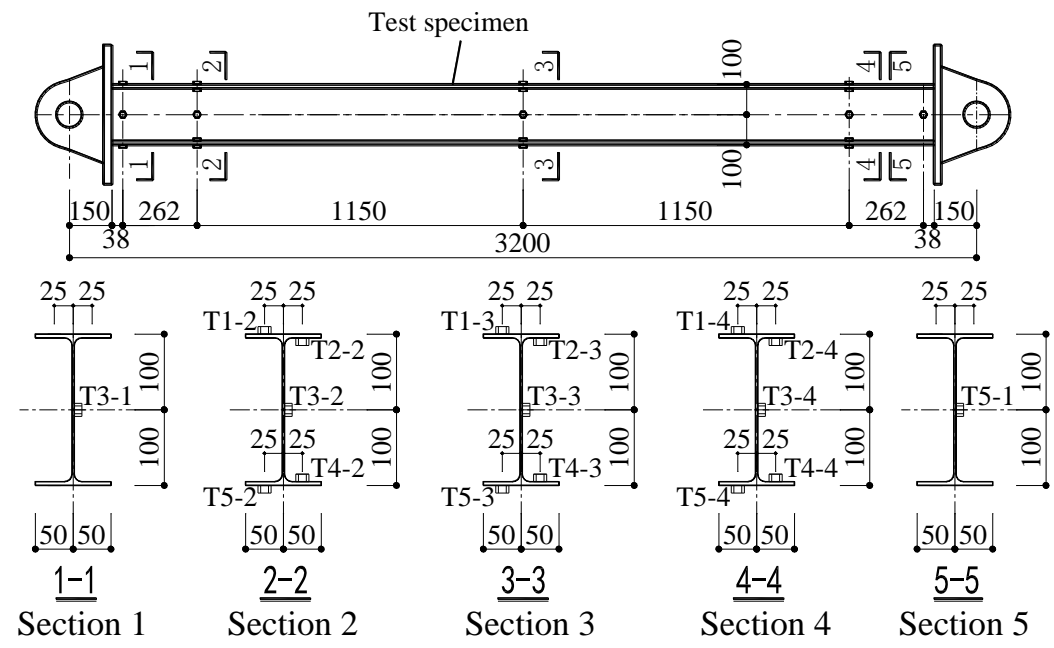

Fig. 11 Thermocouple measurement points arranged on the surface of specimen

The loading ratio $n$ is the ratio between the maximum mid-span bending moment caused by external load $M_{\max }$ and the flexural capacity of beam at room temperature $M_{\mathrm{u}}$, as shown in Eq. (1). The loading ratio $n$ of specimen is a crucial parameter to restrained steel beam fire test. In this study, the bearing capacity test of steel beam at room temperature was not carried out, the flexural capacity of beam $M_{\mathrm{u}}$ was calculated by finite element software ABAQUS [34].

$n=\frac{M_{\max }}{M_{\mathrm{u}}}$

In the event of an excessive loading ratio, the recorded data points will be limited and the specimen will be prematurely destroyed; in the event of an small loading ratio, the test time and the test cost will be excessive. Considering these factors, the loading ratio $n$ was selected as 0.34 and 0.48 in this fire test.

\subsection{Test procedure}

The specific steps of restrained steel beam fire test are as follows: 1) Install the self-made horizontal reaction frame.

2) Install test specimen. To simulate the 3 -side heated fire condition of the steel beam with constraints, the upper flange of specimen was wrapped with fireproof wool. Fig. 12 shows the test specimen after installation.

3) Arrange loading device. The loading system consisted of the distribution beam, $300 \mathrm{kN}$ hydraulic separate jack and $200 \mathrm{kN}$ pressure sensor. Fig. 13 shows the arrangement of the loading system.

5) Link up thermocouple wires and linear displacement meter to the data acquisition device.

6) Apply load on the test specimen and keep the load constant.

7) Heat up the fire test furnace by ISO-834 standard fire curve and record data.

8) End the experiment. According to the relevant provisions of the Internal Standard ISO 834 [40], the failure criteria for beam members under fire is that the mid-span deformation exceeds $L^{2} /(400 d) \mathrm{mm}$ or the mid-span deformation speed reaches $L^{2} /(9000 d) \mathrm{mm} / \mathrm{min}$ ( $d$ is section height of the beam, $L$ is the net span of the beam). That is, when the mid-span vertical deformation of steel beam meets the criteria, it is considered that the steel beam fails under fire. However, this paper is focused on the development of catenary action in the restrained steel beam under fire. In accordance with the above criteria, the restrained steel beam may not occur catenary action before the end of test. Therefore, in the restrained steel beam fire test, the steel beam should be deformed as much as possible. In view of the limitations of the test conditions, the end condition of fire test for each specimen is preliminarily set as: the deformation value at mid span of the 
specimen exceeds $L / 14$.

9) Observe the experimental phenomena.

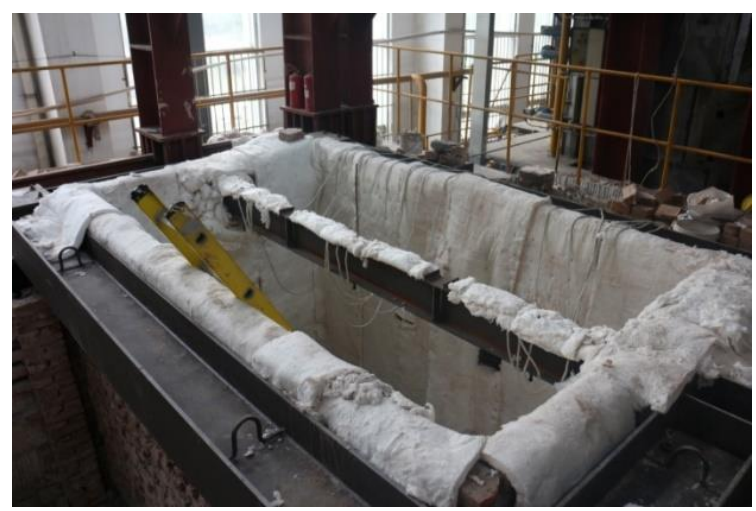

Fig. 12 Installation of the specimen

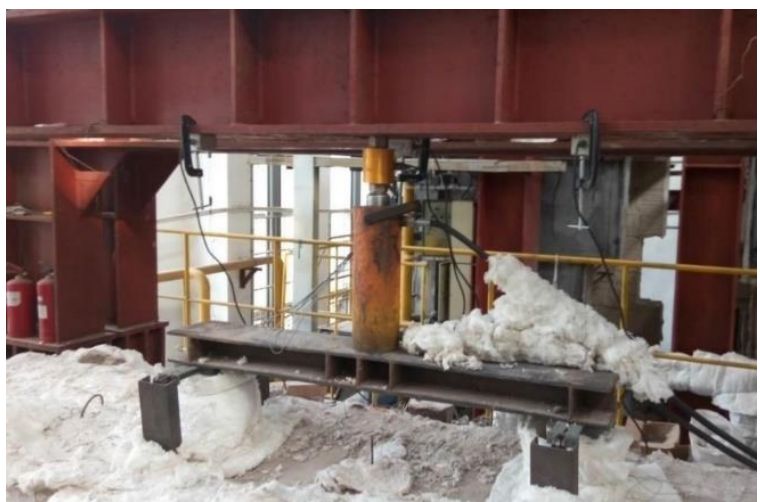

Fig. 13 Arrangement of the loading devices

\subsection{Experimental phenomena}

The specimens (B-1 B-5) had similar experimental phenomena: (1) the air temperature of fire test furnace had a rapid increase; (2) at the beginning of heating, the specimen temperature was obviously lower than the furnace temperature and increased slowly; and (3) the mid-span vertical deformation of specimen grew slowly at first. Due to limited space, only the specific experimental phenomena of specimen B-1 was described.

During the fire test on specimen B-1, the following experimental phenomena can be observed by the data acquisition system: (1) At the beginning of test, as the surface temperature of specimen increased, the mid-span vertical deformation of specimen grew slowly. (2) In approximately 8 mins, the furnace temperature rose to $574{ }^{\circ} \mathrm{C}$. While the surface temperature of specimen had a slow increase, the mid-span vertical deformation of specimen rapidly increased. (3) In approximately $13 \mathrm{mins}$, the furnace temperature rose to $640{ }^{\circ} \mathrm{C}$, and the vertical deformation at mid span of specimen was $244 \mathrm{~mm}$, which was greater than $228 \mathrm{~mm}(L / 14=228 \mathrm{~mm}$, that is the end condition of test). The specimen was judged to be failed. (4) After the end of test, the mid-span deformation of specimen gradually rebounded and was finally maintained at $213 \mathrm{~mm}$.

After the end of test, when the furnace temperature dropped to room temperature, the fire test furnace was opened, and the experimental phenomena and failure mode of specimen B-1 were observed as follows: (1) The specimen mainly had in-plane bending deformation, and the mid-span deformation was large, which was far beyond the specification limits, as shown in Fig. 14(a). (2) A small out-of-plane shift of the upper and lower flanges, which was approximately $13 \mathrm{~mm}$, can be observed at the mid span, as revealed in Fig. 14(b); (3) The specimen surface under fire became reddish brown, and the web became gray-black. The color of the non-fire area (protection of fire-resistant wool) was the same as the color of normal steel (room temperature). (4) Tiny grains were observed on the flange and web of the specimen, as shown in Fig. 14(c).

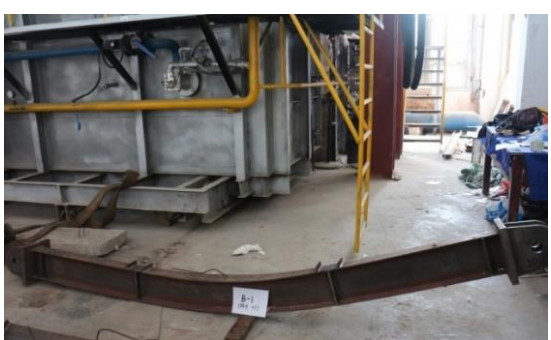

(a) Overall deformation

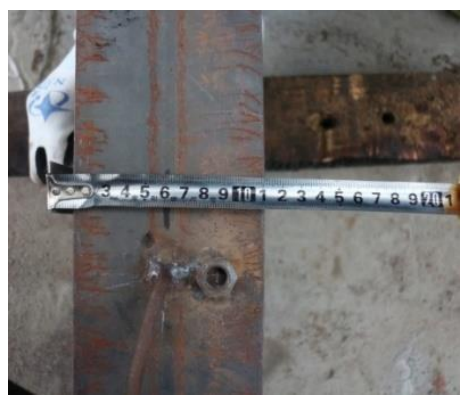

(b) Out-of-plane lateral deformation

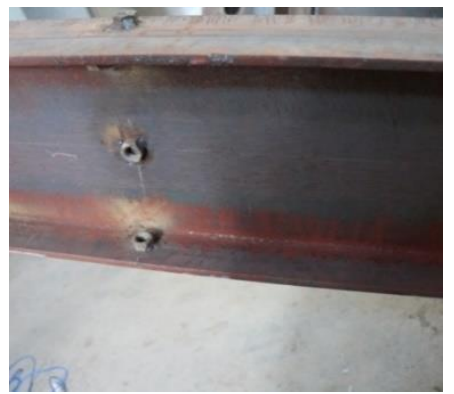

(c) Local tiny grains

Fig. 14 Test phenomena of specimen B-1

The failure mode of specimens B-1 B-5 is shown in Fig. 15. According to Fig. 15: (1) After the failure of the five specimens, the mid-span deformation value considerably exceeded the standard limit. The deformation modes of all specimens were equivalent. (2) All five specimens exhibited distinct catenary action after the fire test. (3) Because the fire duration and surface temperature of the specimens were almost equivalent, the surface color of the specimens was similar.
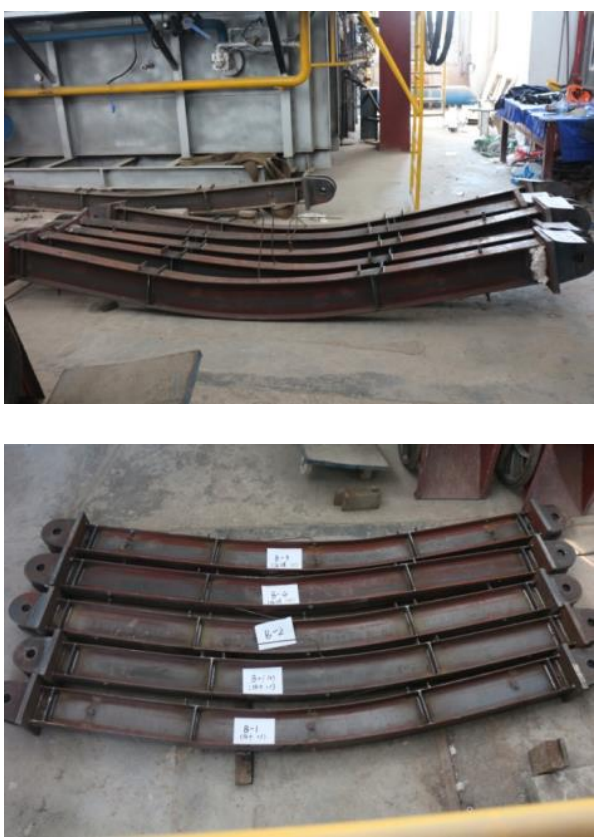


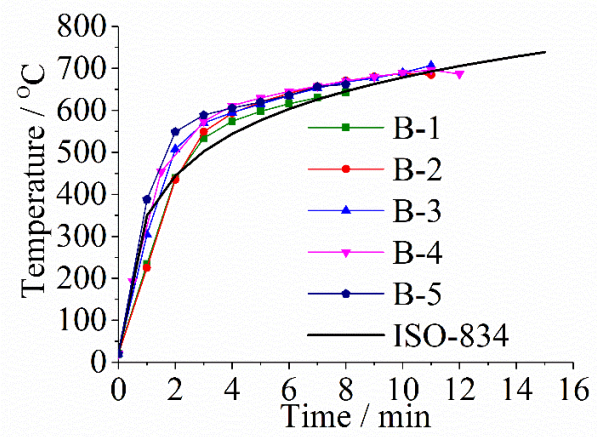

Fig. 16 Furnace temperature curves of specimens B-1 B-5

\subsection{Experimental results}

\subsubsection{Furnace temperature}

The ISO-834 standard fire curve is very rapid at the initial stage, the temperature should be heated up to $300{ }^{\circ} \mathrm{C}$ within $1 \mathrm{~min}$. But it is difficult for horizontal fire test furnace to rise to this temperature in such a short time.
Therefore, in the actual heating process of fire test, the manual control mode is used to preheat the furnace chamber. When the furnace temperature reaches $200 \sim 300{ }^{\circ} \mathrm{C}$, the fire test furnace is switched to the automatic control mode to raise the temperature by following the ISO-834 fire curve. Four thermocouples that installed in the horizontal fire furnace are used to measure the air temperature of fire furnace. Fig. 16 illustrates the furnace temperature - time curves of all specimens and ISO-834 curve, without displaying the temperature data before auto control stage. From Fig. 16, it can be seen the furnace temperature curves of five specimens are similar to ISO-834 curve, and the variation trend is consistent.

\subsubsection{Surface temperature of specimen}

For specimens B-1 B-5, the temperature rising curves of all measurement points set on the specimens are shown in Fig. 17(a) (e). The five temperature measurement points along the height direction of specimen are respectively denoted as T1, T2, T3, T4 and T5. The temperature values of T1, T2, T3, T4 and T5 are the average temperature values of the corresponding positions in section 2 , section 3 and section 4, respectively. For instance, the temperature value of $\mathrm{T} 1$ is the average of the temperature values of measurement points T1-2, T1-3 and $\mathrm{T} 1-4$, and the temperature values of $\mathrm{T} 2, \mathrm{~T} 3, \mathrm{~T} 4$ and $\mathrm{T} 5$ can be similarly calculated. $T_{\mathrm{E}}$ is the average temperature value of the measured points in section 1 and section 5 .

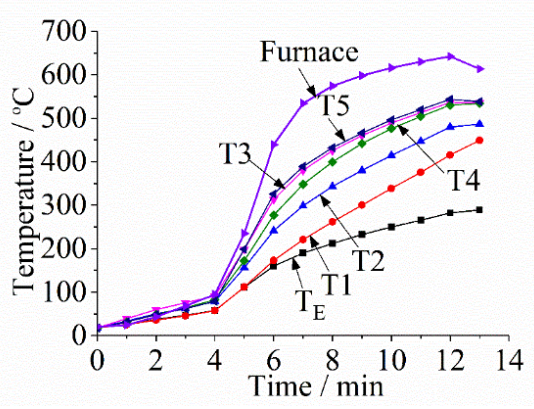

(a) B-1

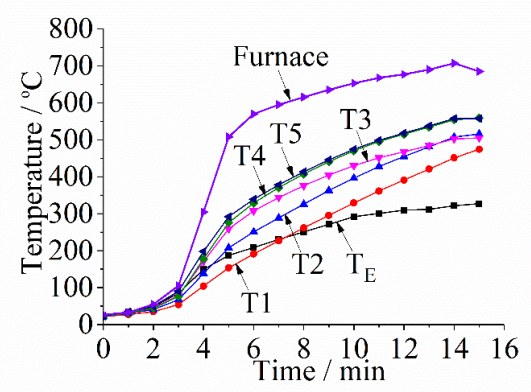

(c) B-3

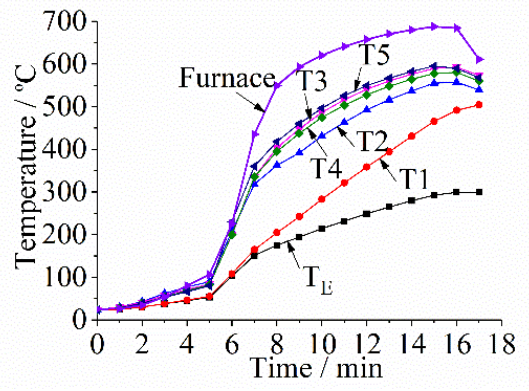

(b) B-2

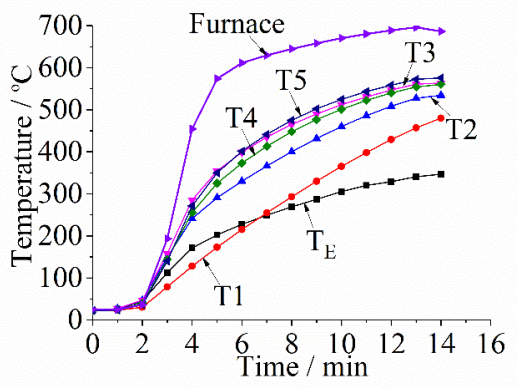

(d) B-4

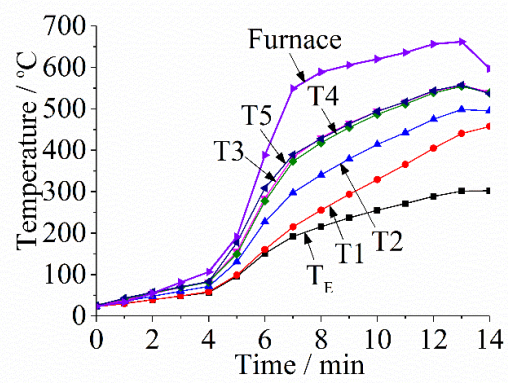

(e) B-5

Fig. 17 Surface temperature rising curves of specimens B-1 B-5

For specimens B-1 $\sim$ B-5, the following conclusions can be obtained from Fig. 17: (1) The furnace temperature is higher than the temperature values measured at the surface of specimen. In the early stage of heating, the difference between the furnace temperature and specimen temperature is large; but in the late stage of heating, the gap between the two decreases, and the curves tend to be similar. (2) The average temperature of the measurement points at the support of specimen $\mathrm{T}_{\mathrm{E}}$ is below $300{ }^{\circ} \mathrm{C}$, which verifies the effectiveness of the support wrapped with fireproof rock wool and ensures that the temperatures at two supports are kept low during the test; (3) The temperature of the measurement point T1 is lower than other measurement points (T2, T3, T4 and T5), and a distinct temperature gradient can be observed along the cross-sectional height direction, which verifies that the specimen is subjected to fire on three sides. 


\subsubsection{Mid-span vertical displacement of specimen}

For specimens B-1 B-5, the mid-span vertical deformation-time curve of each specimen is shown in Fig. 18. As shown in Fig. 18, the heating process of the specimens can be divided into four stages: the initial stage, the middle stage, the late stage and the cooling stage.

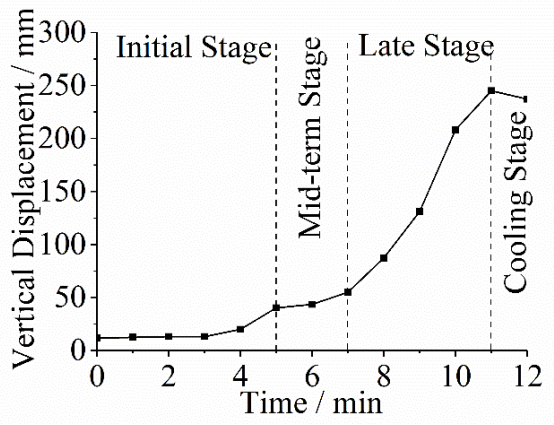

(a) B-1

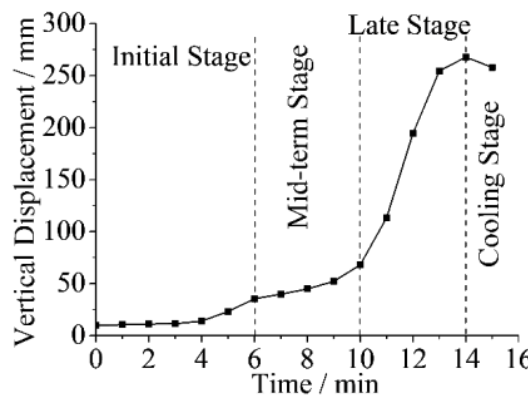

(b) B-2

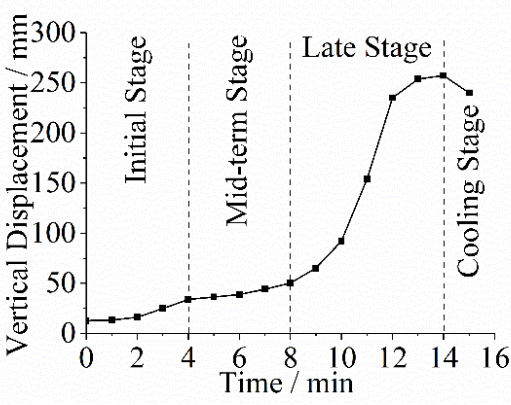

(c) B-3

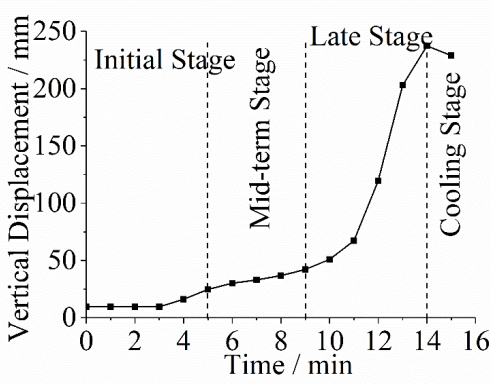

(d) B-4

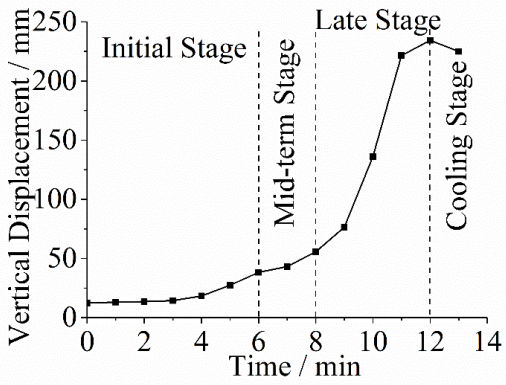

(e) B-5

Fig. 18 Mid-span vertical deformation curve of specimen

(1) In the initial stage (period of slow growth in vertical displacement), the furnace temperature and specimen surface temperature are very low. The specimen stiffness has no attenuation, and the growth rate of vertical displacement in the mid-span is slow. The furnace temperature continually rises, as well as the specimen surface temperature. The specimen stiffness begins to decay, and the increase in the mid-span vertical displacement is accelerated.

(2) In the middle stage (period of continuous growth in vertical displacement), the specimen surface temperature rapidly increases with a continual increase in furnace temperature. The specimen stiffness significantly decreases, and the vertical displacement in the mid-span continues to increase. But for temperature growth rate, the upper flange is faster than the lower flange, which causes the thermal expansion and deformation rate of the upper flange to be greater than the thermal expansion and deformation rate of the lower flange. An inverted arch appeared in the mid-span. The increase in mid-span vertical displacement is restrained to some extent, and the growth rate of the mid-span vertical displacement decreases.

(3) In the late stage (period of rapid growth in vertical displacement), the temperatures are very high and the specimen stiffness presents a distinct attenuation. The vertical displacement in the mid-span rapidly increases until the specimen is failed.

(4) In the cooling stage (period of recovery of elastic deformation), with the decrease of furnace temperature, the surface temperature of specimen decreases, and the stiffness of specimen has some recovery. The vertical displacement of the specimen decreases, and finally no longer changes.

\subsection{Analysis of experiment data}

3.7.1. Comparison of mid-span vertical displacement of specimens under different loading ratios

According to Table 3, two sets of specimens are selected: in the first group, the constraint conditions at both ends of specimens B-1 and B-2 are Constraint Position 1; in the second group, the constraint conditions at both ends of specimens B-3 and B-4 are Constraint Position 2. In the same group, the two specimens have the same section size and constraint conditions, but different loading ratios. Fig. 19 shows the comparison of mid-span vertical displacement of specimens under different loading ratios in two groups.

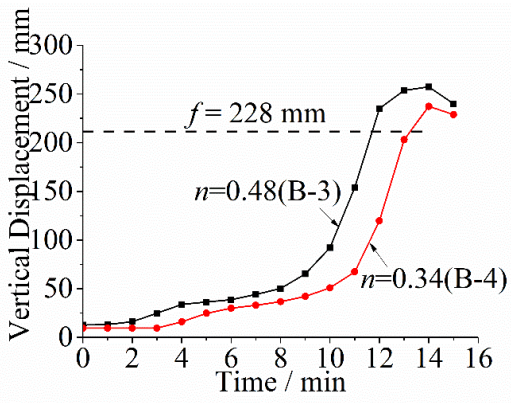

(b) B-3 and B-4

(a) B-1 and B-2

Fig. 19 Comparison of mid-span vertical deformation under different loading ratios

From Fig. 19, it can be seen that the loading ratio has great influences on the development of catenary action of restrained steel beam under fire. When the specimens have the same axial restraint stiffness, with the increase of loading ratio, the catenary action will happen earlier in the restrained steel beam and the phenomenon will be more distinct. 
3.7.2. Comparison of mid-span vertical displacement of specimens under different axial constraints

According to Table 3, two groups of specimens can be selected: in the first group, the loading ratio $n$ of specimens B-1 and B-3 is 0.48 ; in the second group, loading ratio $n$ of specimens B-2 and B-4 is 0.34 . In the same group, the two

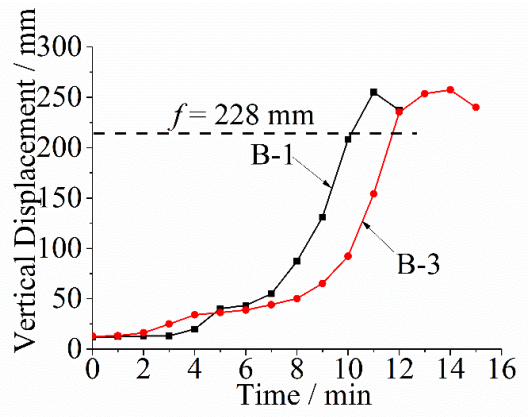

(a) B-1 and B-3 specimens have the same section size and loading ratio, but different constraint conditions at the ends of specimen. Fig. 20 shows the comparison of the midspan vertical displacement of specimens under different axial constraints in two groups.

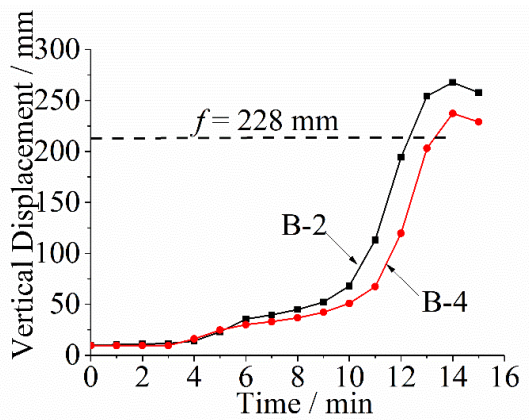

(b) B-2 and B-4

Fig. 20 Comparison of mid-span vertical deformation under different axial restraint stiffnesses

From Fig. 20, it can be seen that the axial restraint stiffness has great influence on the catenary action of restrained steel beam under fire. When the specimens have the same loading radio, with the increase of axial restraint stiffness, the catenary action will happen earlier in the restrained steel beam and the phenomenon will be more distinct.

3.7.3. Comparison between mid-span vertical displacement and loading-point vertical displacement

Fig. 21 illustrates the comparison between mid-span vertical displacement and loading-point vertical displacement of specimens B-1 B-4. According to Fig. 21, (1) In the initial and middle stages, the mid-span vertical displacement

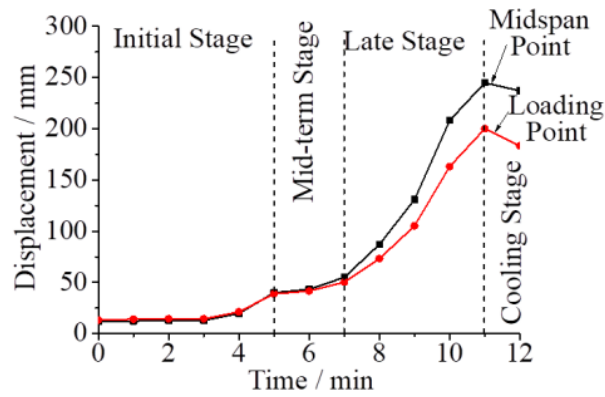

(a) B-1

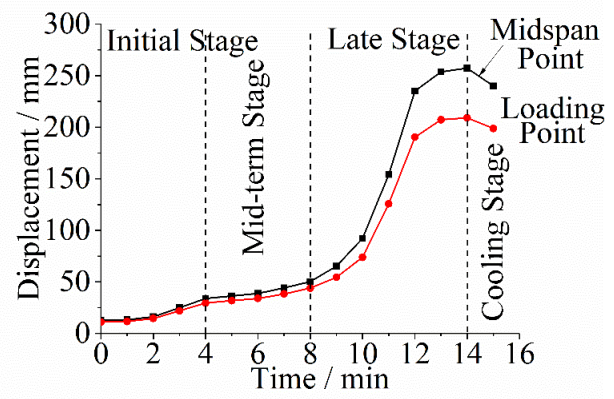

(c) B-3 of specimen is the same as the loading-point vertical displacement of specimen (2) In the later stage, the increase rate of vertical displacement at mid-span is greater than the increase rate of vertical displacement at loading point, and the difference between mid-span vertical displacement and loading-point vertical displacement is larger and larger. This phenomenon can be explained as follows: in the later stage, Due to the high internal temperature of the specimen, the specimen stiffness has a distinct attenuation, the mid-span deformation sharply increases; a large axial tension force occurs in the section of specimen, and the deformation mode changes from mode A to mode B, as shown in Fig. 22(a) and (b), which indicates that the specimen has produced distinct catenary action.

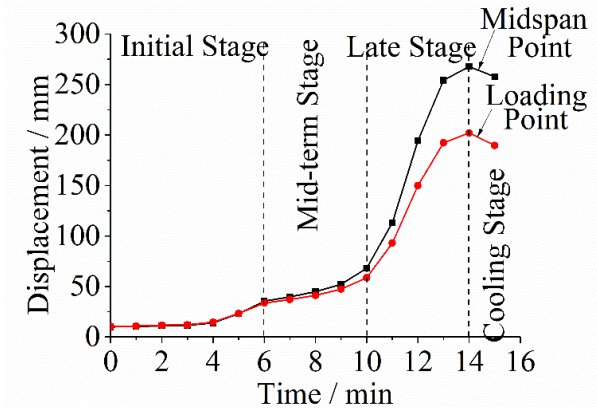

(b) B-2

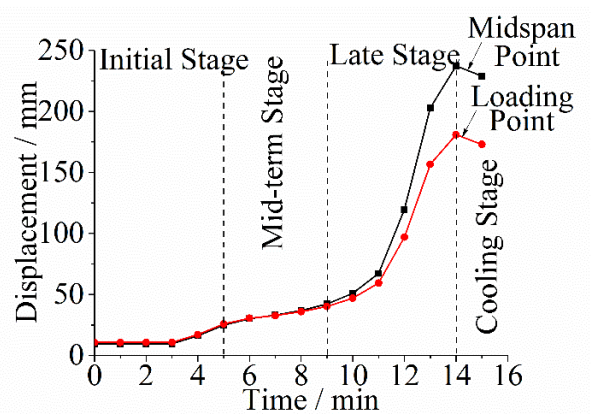

(d) B-4

Fig. 21 Mid-span / loading point vertical deformation of specimen

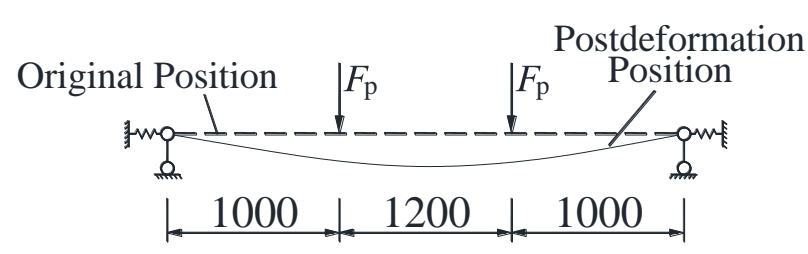

(a) Mode A

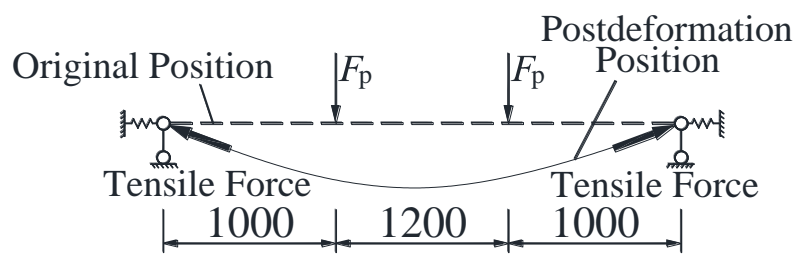

(b) Mode B 


\subsection{Failure modes and results of specimens}

The fire test results of five $\mathrm{H}$-section restrained steel beam specimens B-1 $\sim$ B-5 are shown in Table 4, including the mid-span vertical displacement, failure temperature and failure mode. The mid-span vertical displacement limit is $1 / 14$ of beam span, which indicates the failure of specimen in the fire test. The failure temperature of each specimen is shown in Table 4. The method to determine the failure temperature of specimen is described as follows: firstly, the heating-up time before the failure of specimen can be given according to Fig. 18, and then the corresponding temperature value can be obtained according to the heatingup time through Fig. 17.

\section{Table 4}

The damage indicators of specimens

\begin{tabular}{|c|c|c|c|c|c|c|c|}
\hline \multirow{2}{*}{ Number } & \multirow{2}{*}{$\begin{array}{c}\text { Load radio } \\
n\end{array}$} & \multirow{2}{*}{$\begin{array}{l}\text { Constraint } \\
\text { position }\end{array}$} & \multicolumn{3}{|c|}{ Mid-span vertical displacement $/ \mathrm{mm}$} & \multirow{2}{*}{$\begin{array}{c}\text { Failure } \\
\text { Temperature } \\
/{ }^{\circ} \mathrm{C} \\
\end{array}$} & \multirow{2}{*}{ Failure mode } \\
\hline & & & Limit & Max & Cool & & \\
\hline B-1 & 0.48 & Position 1 & 228 & 244 & 213 & 509 & In-plane overall bending \\
\hline B-2 & 0.34 & Position 1 & 228 & 267 & 231 & 559 & In-plane overall bending \\
\hline B-3 & 0.48 & Position 2 & 228 & 255 & 224 & 516 & In-plane overall bending \\
\hline B-4 & 0.34 & Position 2 & 228 & 238 & 206 & 575 & In-plane overall bending \\
\hline B-5 & 0.48 & Position 1 & 228 & 234 & 203 & 531 & In-plane overall bending \\
\hline
\end{tabular}

As shown in Table 4, (1) the mid-span vertical displacements of specimens B-1 B-5 exceeded $1 / 14$ of the span before they were damaged, which indicates that all specimens occoured obvious catenary action during the test; (2) for restrained steel beams with the same axial restraint stiffness but different loading ratio, the loading ratio has a great influence on the development of catenary action and the failure temperature of specimen; the greater the loading ratio, the earlier the catenary action happens in the specimen, the lower the failure temperature; (3) for restrained steel beams with the same loading ratio but different axial restraint stiffness, the axial restraint stiffness has a certain influence on the development of catenary action and the failure temperature of specimen; the greater the axial restraint stiffness, the later the catenary action happens in the specimen, and the higher the buckling temperature; and (4) the failure modes of specimens B-1 B-5 in the fire test are all in-plane overall bending.

\section{Conclusion}

In this paper, the development of catenary action in the restrained $\mathrm{H}$-section steel beam under fire is experimentally investigated. The following conclusions can be obtained from the experiment:

(1) In the test, the surface temperature distribution of specimen conforms to the condition of fire on three sides, there is an obvious temperature gradient along the height of specimen section, and the surface temperature decreases from bottom to top; the surface temperature distribution of specimen is uniform along the length of specimen.

(2) In the restrained steel beam fire test, when the specimens failed, the

\section{References}

[1] China Public Security Fire Department. 2014 China fire statistics yearbook. Beijing, Chinese People's Public Security University Press; 2014.

[2] Li G Q, Wu B, Han L H. Development of the Research on Fire-Resistance of Structures. Progress in Steel Building Structures, 2006,8(1):1-13

[3] Wei D, Sun X S, Liu Y H, et al. Advances in Study on Fire Resistance of Steel Structures. Progress in Steel Building Structures, 2006,8(4):17-22

[4] Wang Y C. An analysis of the global structural behaviour of the Cardington steel-framed building during the two BRE fire tests. Engineering Structures, 2000; 22(5):401-412.

[5] Burgess I W, Rimawi J El, Plank R J. Studies of the behaviour of steel beams in fire. Journal of Constructional Steel Research, 1991; 19(4): 285-312.

[6] Usmani A S, Lamont S, et al. Fundamental principles of structural behavior under the thermal effects. Fire safety journal, 2001; 36(8): 721-744.

[7] Liu T C H, Fahad M K, Davies J M. Experimental investigation of behaviour of axially restrained steel beams in fire. Journal of Constructional Steel Research, 2002; 58(9):12111230

[8] Moss P J, Buchanan A H, Seputro J, et al. Effect of support conditions on the fire behaviour of steel and composite beams. Fire and materials, $2004 ; 28(2-4): 159-175$

[9] Wang Y C. The importance of considering whole structural behaviour in fire. International Symposium on Structures in Fire, 2002; 10: 119-132.

[10] Yin Y Z, Wang Y C. A numerical study of large deflection behaviour of restrained steel beams at elevated temperatures. Journal of Constructional Steel Research, 2004; 60(7): 1029-1047.

[11] Yin Y Z, Wang Y C. Analysis of catenary action in steel beams using a simplified hand calculation method, Part 1: theory and validation for uniform temperature distribution. Journal of Constructional Steel Research, 2005; 61(2): 183-211.

[12] Yin Y Z, Wang Y C. Analysis of catenary action in steel beams using a simplified hand calculation method, Part 2: validation for non-uniform temperature distribution. Journal of Constructional Steel Research, 2005; 61(2): 213-234

[13] Wang Y C. A review of the behavior of steel structures in fire and a suggestion for future experiment. Proceedings of the international seminar on steel structure in fire, Shanghai, 2001; 40-55.

[14] Dwaikat M M S, Kodur V K R. A performance based methodology for fire design of restrained steel beams. Journal of Constructional Steel Research, 2011; 67(3): 510-524.

[15] Li G Q, He J L, Jiang S C. Fire-resistant experiment and theoretical calculation of a restrained vertical deformation at mid span exceeded $1 / 14$ of beam span, and obvious catenary action appeared in the specimen. Therefore, it is appropriate to select the mid-span deformation of specimen to reach $1 / 14$ of beam span as the judgement condition for the occurrence of catenary action in the restrained steel beam under fire.

(3) The axial restraint stiffness and loading ratio have great influences on the development of catenary action in a restrained steel beam under fire. The larger the loading ratio, the earlier the catenary action occurs in the specimen, the lower the failure temperature of specimen; the larger the axial restraint stiffness, the later the catenary action occurs in the specimen, the higher the failure temperature.

\section{Data availability statement}

Some or all data, models, or code that support the findings of this study are available from the corresponding author upon reasonable request.

\section{Acknowledgments}

The authors gratefully acknowledge the financial support of the National Natural Science Foundation of China (No. 51378105 and No. 51878146), National Key Research and Development Program of China (No 2017YFC0703802). The research was also sponsored by Qing Lan Project in Jiangsu Province and Scientific Research Foundation of Graduate School of Southeast University.

steel beam. China Civil Engineering Journal, 2000; 33(4): 23-26.

[16] Li G Q, Guo S X. Analysis of restrained steel beams subjected to temperature increasing and descending Part I: Theory. Journal of Disaster Prevention and Mitigation Engineering, 2006; 26(3): 241-250.

[17] Guo S X, Li G Q. Analysis of restrained steel beams subjected to temperature increasing and descending Part II: Validation and Parametrical Analysis. Journal of Disaster Prevention and Mitigation Engineering, 2006; 26(4): 359-368.

[18] Li G Q, Guo S X. Analysis of restrained steel girders with large deflection subjected to elevated temperature. Journal of Tongji University (Natural Science), 2006; 34(7): 853-858.

[19] Cong S P. Experimental investigation of behaviour of H-Section steel beam under fire. Thesi (Master). QingDao: School of Civil Engineering, QingDao University of Technology; 2004.

[20] Li X D, Dong Y L, Cong S P. Anti-fire experimental research on H-section steel beams. Building Structure, 2006; 8: 94-102.

[21] Luan Y P, Xi F. Comparative analysis of different restrained beams in fire condition. Journal of Shandong Jianzhu University, 2012; 27(5): 477-482.

[22] Ma N. Catenary action of the restrained castellated steel beams in a fire. Thesis (Master) Jinan: School of Civil Engineering, Shandong University; 2015.

[23] Iqbal N, Heistermann T, Veljkovic M, Lopes F. Axial force and deformation of a restrained steel beam in fire - Description and validation of a simplified analytical procedure. Advanced Steel Construction, 2016; 12(2): 174-193

[24] Du E, Shu G, Tang Y, et al. Experimental investigation on temperature evolution of steel beams in natural fires. Advanced Steel Construction, 2020; 16(4): 328-336.

[25] Liu C. Catenary action of restrained corrugated web steel beams in a fire. Thesis ( $\mathrm{PhD})$. Jinan: School of Civil Engineering, Shandong University; 2017.

[26] National Standard of the People's Republic of China. Metallic materials-Tensile testing Part 1: Method of test at room temperature (GB/T 228.1-2010). Beijing, China Standards Press; 2010.

[27] National Standard of the People's Republic of China. Metallic materials-Tensile testing Part2: Method of test at elevated temperature (GB/T 228.2-2015). Beijing, China Standards Press; 2015.

[28] Wang W Y, Wang K, Kodur V K, Wang B. Mechanical properties of high strength Q690 steel at elevated temperature. Journal of Materials in Civil Engineering, 2018; 30(5):04018062.

[29] $\mathrm{Li} \mathrm{Y,} \mathrm{Li} \mathrm{W} \mathrm{G,} \mathrm{Zhang} \mathrm{X} \mathrm{H,} \mathrm{et} \mathrm{al.} \mathrm{Modeling} \mathrm{of} \mathrm{temperature} \mathrm{dependent} \mathrm{yield} \mathrm{strength} \mathrm{for}$ stainless steel considering nonlinear behavior and the effect of phase transition. Construction and Building Materials, 2018; 159: 147-154. 
[30] Chen W, Ye J H. Steady state experimental investigation of G550 high strength cold-formed steel material at elevated temperatures. China Civil Engineering Journal, 2012; 45(6): 33-42.

[31] Fan S G, Jia L L, Lyu X, Sun W J, Chen M H, Zheng J C. Experimental investigation of austenitic stainless steel material at elevated temperatures. Construction and Building Materials, 2017; 155: 267-285.

[32] Eurocode 3: Design of steel structures-Part 1-2: General rules-structural fire design. European Committee for Standardization, ENV 1993-1-2, CEN, Brussels, 2005.

[33] National Standard of the People's Republic of China. Technical code for fire safety of steel structure in buildings (CECS 200:2006). Beijing, China Planning Press; 2006.

[34] ABAQUS. ABAQUS/Standard user's manual volumes I-III and ABAQUS CAE Manual, version 6.4. Pawtucket (USA): Hibbitt, Karlsson \& Sorensen, Inc.; 2003.

[35] Guo S X. The behaviour of restrained steel beam during heating and cooling and the damage of beam-to-column connection Thesis (PHD). Shanghai: School of Civil Engineering, Tongji University; 2006

[36] Xia X F. Theoretical analysis and experimental research on fire resistance of stainless steel beam. Thesis (Master). NanJing: School of Civil Engineering, Southeast University; 2014

[37] Fan S G, He B B, Xia X F, et al. Fire resistance of stainless steel beams with rectangular hollow section: Experimental investigation. Fire Safety Journal, 2016; 81 (1): 17-31.

[38] Gardner L, Baddoo N R. Fire testing and design of Stainless Steel Structures. Journal of Constructional Steel Research, 2006; 62(6): 532-543

[39] Ernest C Y T, Young B. Performance of cold-formed stainless steel tubular columns at elevated temperatures. Engineering Structures, 2008; 30 (1): 2012-2021.

[40] Internal Standard ISO 834. Fire-resistance tests - Elements of building construction — Part 1: General requirements (ISO 834-1:1999). ISO, 1999. 